\title{
Integrating Oral Medicine within Saudi Arabia's Healthcare Systems
}

\author{
Abdullah Alsoghier \\ Department of Oral Medicine and Diagnostic Sciences, King Saud University, Riyadh, Saudi Arabia
}

Dear Editor,

I write with reference to the informative review conducted by Bindakhil et al. [1] about the essence of oral medicine (OM) in healthcare systems, specifically in Saudi Arabia. This review highlighted the need for multidisciplinary teamwork in OM clinical practices, which frequently include managing oral chronic conditions that could be painful, affecting the oral health-related quality of life and perhaps be life-threatening [2,3].

The delivery plan for the Kingdom of Saudi Arabia's 2030 Health Sector Transformation Program addresses such inter-professional workforce integration to maintain a value-based healthcare service to meet the patient and population needs [4]. In addition, the newly appointed Public Health Commission earlier this year, which replaced the National Centre of Disease Control, stated their objectives which were relevant to the OM scope of practice [5]. These include investigating and assessing risk factors and diseases that could compromise public health (e.g., tobacco use), promoting the guidelines for preventive and value-based healthcare services (e.g., early detection of premalignant lesions in high-risk groups), establishing databases for diseases and conditions of concern to the community health (e.g., oral cancer), and discerning public health priorities (e.g., oral health-related quality of life).

In line with other parts of the world [6], the OM units in the KSA are mainly based in academic institutions and governmental hospitals [7]. The previous study included 75 clinicians registered with the local health registration body (The Saudi Commission for Health Specialties) and responded to their study invitation. Notably, $89 \%$ were based in public universities and hospital settings, whereas $73 \%$ were identified as specialists or consultants. Nevertheless, these figures might be an approximate reflection as the response rate was not reported in the study (i.e., how many invitations were sent/responded?). Moreover, there was no clear indication that these specialists/consultants obtained "OM qualification" as some might be qualified in another speciality of a related scope of practice (e.g., oral and maxillofacial surgery, special care dentistry, and orofacial pain). Thus, information about the estimated number of OM practitioners in Saudi and the number of patients seen by those practitioners is yet lacking [1]. It is also notable that some OM units of the public hospitals have allocated the patient's access for treatment primarily to their employees.

There however remain differences in OM practices within different worldwide healthcare schemes, perhaps due to the recent recognition of OM as a speciality compared to other medical and dental specialities with the lack of consensus on its definition and scope of practice [8]. Similar considerations were highlighted in the earlier review by Bindakhil et al. [1] toward the OM practice in Saudi. To address these limitations, several steps could help better recognition and integration within healthcare systems in the KSA. For instance, increasing the public fund for $\mathrm{OM}$ services and promoting the web-based sources to locate the OM units available within the area by patients and healthcare professionals. In addition, $\mathrm{OM}$ could be actively integrated into the curricula, clinical ro-
(C) 2022 The Author(s)

Published by S. Karger AG, Basel

This is an Open Access article licensed under the Creative Commons Attribution-NonCommercial-4.0 International License (CC BY-NC) (http://www.karger.com/Services/OpenAccessLicense), applicable to the online version of the article only. Usage and distribution for commercial purposes requires written permission.
Correspondence to:

Abdullah Alsoghier, aalsoghier@ksu.edu.sa 
Table 1. A list of possible areas of collaboration between oral medicine specialists and other healthcare providers

\begin{tabular}{|c|c|}
\hline $\begin{array}{l}\text { Healthcare practitioner/ } \\
\text { speciality }\end{array}$ & Aspects of possible multidisciplinary collaboration \\
\hline Allergist & $\begin{array}{l}\text { Oral and dental health considerations with allergies (e.g., oral allergy syndrome and orofacial } \\
\text { granulomatosis) }\end{array}$ \\
\hline Cardiologist & Antibiotic prophylaxis for dental treatment \\
\hline Dietitian & $\begin{array}{l}\text { Oral Crohn's and orofacial granulomatosis } \\
\text { Oral hyposalivation and high decayed-missing-filled teeth index } \\
\text { Gluten sensitivity enteropathy } \\
\text { Eating disorders (e.g., anorexia and bulimia nervosa) } \\
\text { Tobacco and alcohol cessation }\end{array}$ \\
\hline ENT & Endoscopy for upper GIT, sinus disorders and tinnitus mimicking orofacial pain \\
\hline Geriatrician & Oral and dental health considerations with Alzheimer's disease, Parkinson's disease, and polypharmacy \\
\hline Geneticist/immunologist & $\begin{array}{l}\text { Oral and dental health considerations with genetic disorders } \\
\text { Oral and dental health considerations with autoinflammatory disorders (e.g., periodic fever, aphthous } \\
\text { stomatitis, pharyngitis, adenitis [PFAPA] syndrome, and hyperimmunoglobulin D syndrome) }\end{array}$ \\
\hline Haematologist & Oral and dental health considerations with vascular disorders and coagulopathies \\
\hline $\begin{array}{l}\text { Internal medicine/ } \\
\text { rheumatologist/ } \\
\text { infectious disease specialist }\end{array}$ & $\begin{array}{l}\text { Oral and dental health considerations with an inflammatory bowel disease (e.g., Crohn's disease and } \\
\text { ulcerative colitis) } \\
\text { Oral and dental health considerations with a rheumatic disease (e.g., rheumatoid arthritis and psoriatic } \\
\text { arthritis) } \\
\text { Oral and dental health considerations with liver and renal diseases or dysfunction } \\
\text { Orofacial pain with complex regional pain syndrome and fibromyalgia } \\
\text { Severe oral involvement or systemic manifestations of bacterial (e.g., tuberculosis and syphilis), fungal } \\
\text { (e.g., chronic mucocutaneous candidiasis), and viral infections (e.g., herpesviridae, hepatitis viruses, and } \\
\text { HIV) }\end{array}$ \\
\hline Obstetrician-gynaecologist & Oral/systemic involvement of lichen planus \\
\hline Orthopaedist & $\begin{array}{l}\text { Oral and dental health considerations with genetic and acquired bone disorders (e.g., cleidocranial } \\
\text { dysplasia and Paget's disease) }\end{array}$ \\
\hline Oncologist & $\begin{array}{l}\text { Assessment and management of head and neck cancer } \\
\text { Oral and dental health considerations with radiation-induced adverse effects to the head and neck }\end{array}$ \\
\hline Ophthalmologist & Eye lesions with autoimmune diseases (e.g., Sjogren's syndrome and pemphigus vulgaris) \\
\hline Paediatrician & Oral and dental health considerations with genetic and metabolic syndromes and rare diseases \\
\hline Pain specialist & $\begin{array}{l}\text { Chronic pain comorbidities (e.g., fibromyalgia, back pain, and sciatica) } \\
\text { Cranial nerve neuralgias (e.g., trigeminal and glossopharyngeal neuralgia) }\end{array}$ \\
\hline Plastic surgeon & $\begin{array}{l}\text { Reconstruction after head and neck cancer treatment } \\
\text { Management of persisted symptoms due to facial nerve palsy }\end{array}$ \\
\hline Preventive medicine & $\begin{array}{l}\text { Oral and dental health considerations with occupational and environmental hazards (e.g., chemical } \\
\text { dental erosion) }\end{array}$ \\
\hline
\end{tabular}

Oral Med and Healthcare Systems in the KSA 
Table 1 (continued)

\begin{tabular}{ll}
\hline $\begin{array}{l}\text { Healthcare practitioner/ } \\
\text { speciality }\end{array}$ & Aspects of possible multidisciplinary collaboration \\
\hline Pulmonologist & Oral and dental health considerations with lung disease (e.g., tuberculosis, sarcoidosis, and COPD) \\
\hline Psychiatrist & Oral and dental health considerations with somatization, personality, and anxiety disorders \\
\hline Psychologist & Psychosocial aspects of orofacial pain and temporomandibular joint disorders \\
\hline Public health & Epidemiological studies concerning oral diseases \\
\hline Sport medicine & Oral and dental health issues of athletes \\
\hline
\end{tabular}

tation, and continued professional development activities of related medical specialities [1].

Moreover, there will be a need to establish referral pathways and multidisciplinary clinics with these specialities, with examples shown in Table 1. Also, there is a high need to support the national clinical and academicbased training programmes to boost the number of OM specialists over the coming years. These programmes could also help to improve the recognition and maintain the flow of patients seen within healthcare systems.

Health professional bodies could help acknowledge potential collaboration with allied specialities for an impactful excellent delivery of patient care [9]. Unfortunately, there is no present specific OM professional body in the kingdom. Thus, establishing a Saudi society for OM could also help to network and collaborate with existing national dental and medical societies. Furthermore, such a society can support the patient and community's health literacy related to oral diseases, provide continued professional development activities, establish national consen- sus and guidelines, and advance epidemiological and clinical research of oral diseases [10]. The importance of these roles is emphasized at the present COVID-19 pandemic, which has profoundly interrupted healthcare services worldwide and indeed those of OM [11].

\section{Conflict of Interest Statement}

The author has no conflicts of interest to declare.

\section{Funding Sources}

No specific funding was received for the present work.

\section{Author Contributions}

A.A.: conceptualization, writing - original draft, and writing - review and editing.

\section{References}

1 Bindakhil M, Charmelo-Silva S, Bin Dakhil AA, Alomair IA. The value of the oral medicine specialty in the modern healthcare systems. Saudi J Health Systems Res. 2021;1(2): 33-40.

2 Scully C, Miller CS, Urizar JMA, Alajbeg I, Almeida OPD, Bagan JV, et al. Oral medicine (stomatology) across the globe: birth, growth, and future. Oral Surg Oral Med Oral Pathol Oral Radiol. 2016;121(2):149-57.

3 Alsoghier A, Riordain RN, Fedele S, Porter S. Psychosocial impacts of oral epithelial dysplasia. J Oral Pathol Med. 2021;50(7):700-7.

42030 SV. Health Sector Transformation Program. Saudi Arabia2021.
5 Ministers BOEaTCo. Prepatory guidelines for the public health commission Saudi Arabia2021. 2021.

6 Stoopler ETDe Rossi SS, Greenberg MS, Sollecito TP. The global footprint of oral medicine specialists: the University of Pennsylvania experience. J Dental Edu. 2016;80(12):1464-7.

7 Al Mohaya MA, Almaziad MM, Al-Hamad KA, Mustafa M. Telemedicine among oral medicine practitioners during COVID-19 pandemic and its future impact on the specialty. Risk Manag Healthc Policy. 2021;14: 4369 .
8 Bez C, Sklavounou A, Carrozzo M. Oral medicine in Europe: past, present and future. $\mathrm{Br}$ Dent J. 2017;223(9):726-8.

9 Henson JW. Developing physician leaders through professional associations. J Healthc Manag. 2016 Jan-Feb;61(1):7-10.

10 Goolsby MJ, DuBois JC. Professional organization membership: advancing the nurse practitioner role. J Am Assoc Nurse Pract. 2017;29(8):434-40.

11 Dziedzic A, Varoni EM. Challenges of oral medicine specialistsat the time of COVID-19 pandemic. Oral Diseases. 2020. 